\title{
Multidimensional potential of boron-containing molecules in functional materials
}

\author{
WOLFGANG KAIM ${ }^{1, *}$ and NARAYAN S HOSMANE ${ }^{2 * *}$ \\ ${ }^{1}$ Institut für Anorganische Chemie, Universität Stuttgart, Pfaffenwaldring 55, \\ D-70550 Stuttgart, Germany \\ ${ }^{2}$ Department of Chemistry and Biochemistry, The Michael Faraday Laboratories, \\ Northern Illinois University, DeKalb, Illinois 60115-2862, USA \\ e-mail: kaim@iac.uni-stuttgart.de
}

\begin{abstract}
Boron-containing molecular systems have received much attention under theoretical aspects and from the side of synthetic organic chemistry. However, their potential for further applications such as optically interesting effects such as Non-Linear Optics (NLO), medical uses for Boron Neutron Capture Therapy (BNCT), or magnetism has been recognised only fairly recently. Molecular systems containing boron offer particular mechanisms to accommodate unpaired electrons which may result in stable radicals as spin-bearing materials. Among such materials are organoboron compounds in which the prototypical electron deficient $\left({ }^{10} \mathrm{~B},{ }^{11} \mathrm{~B}\right)$ boron vs. carbon centers can accept and help to delocalise added electrons in a 2-dimensionally conjugated $\pi$ system. Alternatively, oligoboron clusters $\mathrm{B}_{\mathrm{n}} \mathrm{X}_{\mathrm{n}}{ }^{\mathrm{k}}$ and the related carboranes or metallacarboranes are capable of adding or losing single electrons to form paramagnetic clusters with 3 -dimensionally delocalised spin, according to combined experimental studies and quantum chemical calculations. The unique nuclear properties of ${ }^{10} \mathrm{~B}$ are of therapeutic value if their selective transport via appended carbon nanotubes, boron nanotubes, or magnetic nanoparticles can be effected.
\end{abstract}

Keywords. Boron compounds; carbon nanotubes; electron spin; organoboranes; radicals; tumour therapy.

\section{Introduction}

As the chemically closest neighbour of carbon in the periodic table, boron and its carbon analogues ${ }^{1}$ (or non-analogues) ${ }^{2}$ have been well-discussed over the last decades. A popular and largely successful approach to devise and interpret \{carbon $\triangleq$ boron\} correlations has been to consider isoelectronic relationships such as (1)-(3) in scheme 1 .

$$
\begin{aligned}
& \mathrm{C} \triangleq \mathrm{B}^{-} \\
& \mathrm{C}^{+} \triangleq \mathrm{B} \\
& \mathrm{C}=\mathrm{C} \triangleq{ }^{-} \mathrm{B}=\mathrm{N}^{+} \\
& \mathrm{C}^{\bullet} \triangleq \mathrm{B}^{\bullet-} .
\end{aligned}
$$

The carbon/borate (1), carbocation/boron (2) and the olefin/iminiumborato (3) analogies have been discussed, also under the materials aspect. Examples

\footnotetext{
*For correspondence
}

include molecules with specifically $\mathrm{C}=\mathrm{C} /{ }^{-} \mathrm{B}=\mathrm{N}^{+}$ exchanged functions, ${ }^{3} \mathrm{~B}_{\mathrm{x}}$ cluster analogues of the fullerenes $\mathrm{C}_{\mathrm{y}},{ }^{4}$ nanoporous $\mathrm{BN}$ and $\mathrm{BCN},{ }^{5}$ or superconducting ${ }^{6} \mathrm{MgB}_{2}\left(T_{c}=39 \mathrm{~K}\right)$ with the hexagonal layers of $\mathrm{B}^{-}$reminiscent of the $\mathrm{C}$ layers in graphite. ${ }^{7}$

The isoelectronic relation (4) between carbon radical and boron anion radical centers has been recognised ${ }^{2,8,9}$ but less extensively researched in comparison to (1)-(3), it will be the main focus of this article.

The electron deficiency of boron as compared to carbon results in the well-known Lewis acidity (= electron pair accepting capability) as well as in the charge accepting capacity of boron functions in excited states which plays an important role e.g. in the use of boryl groups for optoelectronic effects (sensing, NLO behaviour). ${ }^{10,11}$ The accommodation of one extra unpaired electron, e.g. through oneelectron reduction or oxidation of suitable precursors, is also a viable option, leading to spin-bearing and thus magnetically interesting systems. ${ }^{2,12}$

Following the electron acceptor capability of boron as apparent from the electronic ${ }^{10,11,13}$ and elec- 

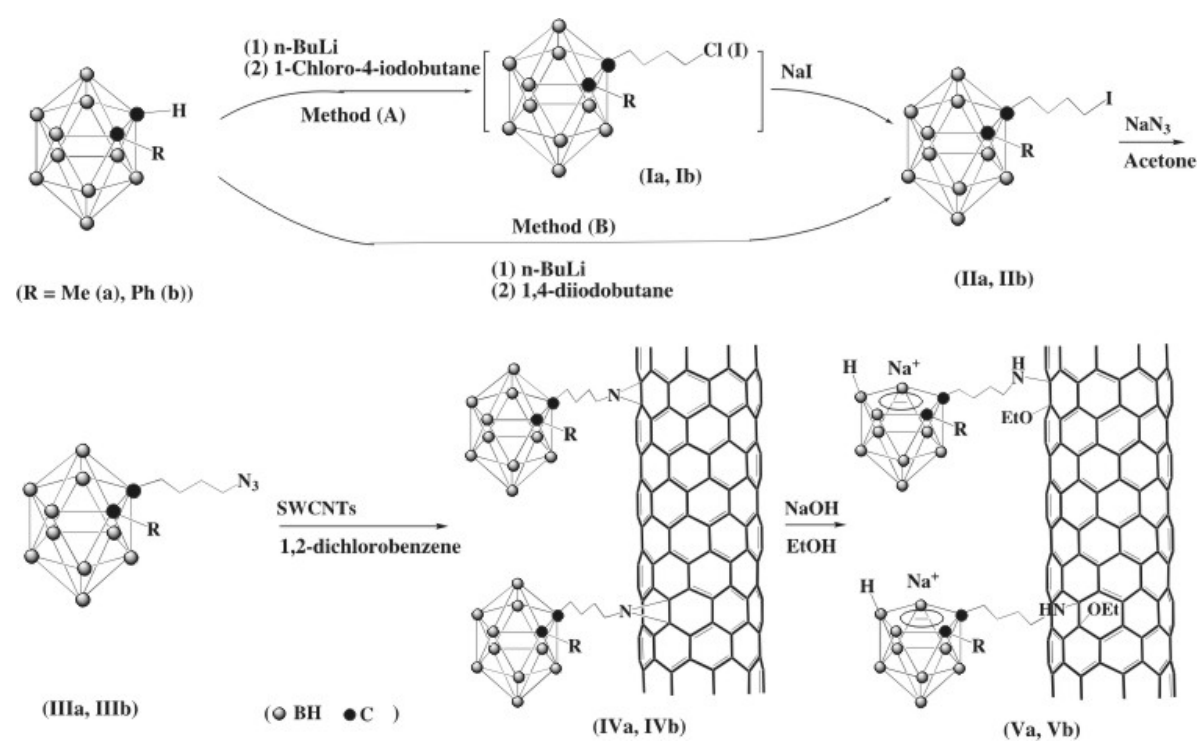

Scheme 1.

trochemical $^{14}$ substituent effects of boryl substituents we start here by presenting selected examples of corresponding spin-carrying organoboron systems. ${ }^{2,12}$ Considering the characteristical cluster chemistry of oligoboranes, carboranes, and metallacaboranes with their electron number rules ${ }^{15}$ and their enormous potential in Boron Neutron Capture Therapy (BNCT) of malignant tumours e.g. of the brain (see Chapter 6-8), ${ }^{16}$ we also describe pertinent radical species with three-dimensionally delocalised spin. ${ }^{12}$

In this paper, we shall outline how the acceptor behaviour of boron and the existence of oligoboranes or carborane clusters can favour the formation and stabilisation of paramagnetic species with partially boron-centered spin, both in the more familiar two-dimensional form of $\pi$ systems, or within threedimensional cluster frameworks. In a review on main group element radicals ${ }^{2}$ Power has noted that some of those species may be considered 'inspired' by analogy with organic counterparts, while others have no organic counterparts. The concepts of boron radical formation and stabilisation will be presented here using selected examples from the literature, and they will be interpreted in the light of less conventional approaches such as mixed-valency, supported by quantum chemical approaches via Density Functional Theory (DFT). Eventually, these species may become viable components e.g. of extended magnetic systems, just as organoboranes have recently found their way into materials with potential for optical (NLO) and electrochemical (sensor) applications, ${ }^{10}$ all due to the acceptor effect of B.
Boron is an excellent element for studying the spin distribution in paramagnetic species because both stable isotopes ${ }^{10} \mathrm{~B}(19.8 \%, I=3)$ and ${ }^{11} \mathrm{~B}$ $(80 \cdot 2 \%, I=3 / 2)$ have nuclear spins and sufficiently large nuclear magnetic moments $\left(\mu\left({ }^{10} \mathrm{~B}\right) / \mu\left({ }^{11} \mathrm{~B}\right)=\right.$ $0 \cdot 335)$. However, the combination of both isotopes with their rather high $I$ values can create very large numbers of hyperfine lines when several B atoms and other active nuclei participate in the interaction with the electron spin, ${ }^{17}$ partially or totally obscuring the spectral information from EPR (electron paramagnetic resonance). In such cases, other methods such as Electron Nuclear Double Resonance (ENDOR) have proven advantages. ${ }^{18,19}$

\section{2. $\pi$ Radicals}

The function of B as acceptor atom can be used in several ways to stabilize radical species. The acceptance of just one electron ('single spin injection') by boranes $\mathrm{BX}_{3}$ should lead to diminished electron deficiency. The corresponding radical anions $\left[\mathrm{BX}_{3}\right]^{\cdot-}$ are isoelectronic with the much studied methyl radicals $\left[\mathrm{CX}_{3}\right]^{\bullet}$ and with aminium radical cations $\left[\mathrm{NX}_{3}\right]^{\circ+}$; reactions of triarylboranes with alkali metals have thus been studied sporadically over the past decades. ${ }^{2,14,20-23}$ Follow-up reactions ${ }^{20}$ to the electron transfer such as B-aryl bond dissociation and association to form borates can preclude the observation of corresponding radical anions, which may yet be stabilised following familiar strategies from organic radical chemistry, i.e. steric shielding to prevent 
bimolecular reactivity, and spin delocalization through $\pi$ conjugation.

It is not surprising, therefore, that 2,4,6-trimethylphenyl (mesityl, Mes) substituents have featured prominently in this area of research. ${ }^{14,21,22}$ The trimesitylborane radical anion was characterised as a fairly stable species with a sizeable ${ }^{11} \mathrm{~B}$ hyperfine coupling constant of about $1.0 \mathrm{mT}^{21}$ despite a rather negative reduction potential. ${ }^{14}$ The ortho-positioned methyl substituents of the mesityl group shield the empty or half-filled $p_{z}$ orbital in boranes or their radical anions from external attack, thereby preventing association reactions.

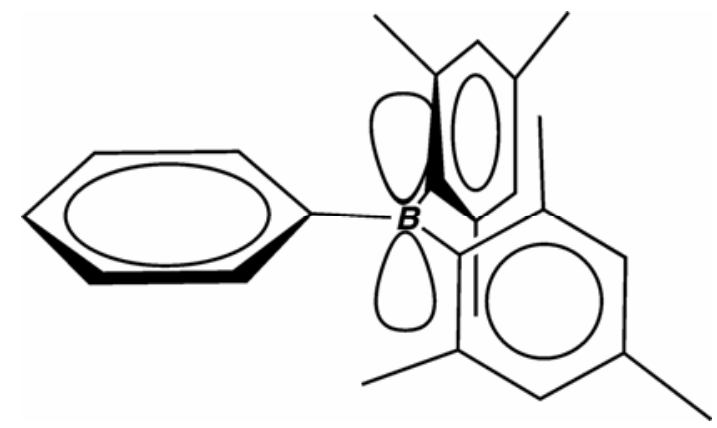

The partially conjugated aromatic ring systems of Mes and of phenyl in mixed systems $\left[\mathrm{BMes}_{n} \mathrm{Ph}_{3-n}\right]^{\circ}$ can accommodate some of the spin and charge ${ }^{14,21}$ one reason why these compounds are not directly formulated as boron(II) systems. Comparative crystal structure analysis of the redox pair $\left[\mathrm{BMes}_{3}\right]^{0 / \boldsymbol{\bullet}}$ confirmed this concept by showing relatively little changes in the overall structure, ${ }^{22}$ implying a rather small reorganisation energy.

An approach to facilitate the electron uptake is the conjugative coupling of two dimesitylborane $\pi$ acceptor groups by a bridging $\pi$ system. $p$-Phenylene and 4,4'-biphenylene bridges have thus been used to conjugatively connect two $\operatorname{Mes}_{2} \mathrm{~B}$ groups $(1,2)$ with the result of two split reduction waves at anodically shifted potentials. ${ }^{14,29,24,25}$ The corresponding radical anion intermediates (1 and 2 ) formed after single spin injection are the "mirror images" ${ }^{24}$ of the stable radical cations of $p$-phenylendiamines, the longknown 'Wurster's salts' first described in 1879 , and of substituted benzidines used as hole transfer components in OLED devices. ${ }^{26}$ The anion radicals 1 and 2 exhibit long-wavelength absorptions ${ }^{25}$ and EPR/ENDOR detectable spin delocalisation to the B centers which leaves relatively little unpaired electron density in the bridging carbon rings. ${ }^{19}$ In fact, only nitro groups exert a more powerful spin with- drawing effect from $p$-phenylene radical anions than dimesitylboryl substituents. ${ }^{14,24}$

However, instead of an acceptor substituted $\pi$ system one may also refer to the species $\mathbf{1}$ and $\mathbf{2}$ as bridged mixed-valent diboron (II, III) compounds. ${ }^{27}$

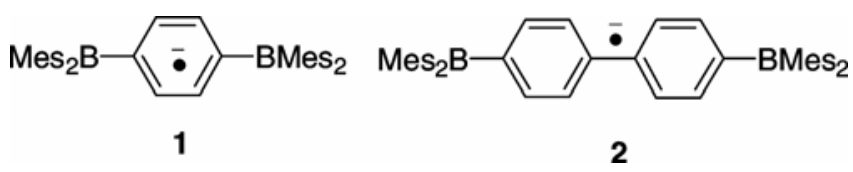

The largely transition metal-associated concept of mixed valency ${ }^{28,29}$ has been applied recently to organic compounds involving coupled hydrazine/ hydrazinium, arylamine/arylaminium and even triarylcarbon radical functions. ${ }^{30}$ Typical phenomena connected with mixed valency are a sizeable splitting of redox processes as quantified by the comproportionation constant $K_{c}(5)$ for the two-step electron transfer (6), and the long-wavelength (low-energy) inter-valence charge transfer (IVCT) transitions of the intermediates (7). ${ }^{28,29}$

$$
K_{c}=\frac{[\operatorname{Int}]^{2}}{[\mathrm{Ox}][\mathrm{Red}]},
$$

$\mathrm{RT} \ln K_{c}=n F \Delta E ; \Delta E=E_{1}-E_{2}$

$$
\begin{aligned}
& \mathrm{R}_{\mathrm{x}} \mathrm{B}^{\mathrm{n}}(\mu-\mathrm{L}) \mathrm{B}^{\mathrm{n}} \mathrm{R}_{\mathrm{x}} \underset{-\mathrm{e}^{-}}{\stackrel{+\mathrm{e}^{-}}{\rightleftharpoons}}\left[\mathrm{R}_{\mathrm{x}} \mathrm{B}^{\mathrm{n}}(\mu-\mathrm{L}) \mathrm{B}^{n-1} \mathrm{R}_{\mathrm{x}}\right]^{-} \\
& \text {Ox } \quad\left(E_{1}\right) \quad \text { Int } \\
& \underset{\mathrm{e}^{-}}{\stackrel{+\mathrm{e}^{-}}{\rightleftharpoons}}\left[\mathrm{R}_{\mathrm{x}} \mathrm{B}^{n-1}(\mu-\mathrm{L}) \mathrm{M}^{n-1} \mathrm{R}_{\mathrm{x}}\right]^{2-} \\
& \left(E_{2}\right) \quad \text { Red }
\end{aligned}
$$

$$
\left[\mathrm{R}_{\mathrm{x}} \mathrm{B}^{\mathrm{n}}(\mu-\mathrm{L}) \mathrm{B}^{n-1} \mathrm{R}_{\mathrm{x}}\right]^{-} \underset{\mathrm{IVCT}}{\stackrel{\mathrm{h} v}{\longrightarrow}} *\left[\mathrm{R}_{\mathrm{x}} \mathrm{B}^{n-1}(\mu-\mathrm{L}) \mathrm{B}^{\mathrm{n}} \mathrm{R}_{\mathrm{x}}\right]^{-},
$$

In the situation of 1 or $\mathbf{2}$ one may describe these ions as Class III species (18) i.e. completely delocalised (symmetrical) mixed-valent $\left(\mathrm{B}^{2.5}\right)_{2}$ systems bridged by carbanionic donors, which would be compatible with a hole-transfer mechanism for the valence exchange. Within the hole-transfer formalism, ${ }^{29 b}$ the electron deficiency ('hole') migrates from the oxidized to the reduced side via a high lying occupied MO of the bridge, resulting in some participation of that bridge in the spin distribution according to MO theory. Large comproportionation constants $K_{c}$ (e.g. $5 \times 10^{11}$ for 1) of the intermediates from (1) and the 
long-wavelength absorption typical of mixed-valent species ${ }^{28,29}$ support the mixed-valence alternative. DFT calculations also confirm this notion, reproducing the low-energy transition between the delocalized singly occupied MO (SOMO) and a mostly boron-centered LUMO. ${ }^{27}$

The DFT calculations for 1 yield a spin distribution with $30 \%$ on each of the B centers and only $32 \%$ in the bridge, ${ }^{27}$ in agreement with the experimental EPR/ENDOR results. ${ }^{19}$ Thus, we conclude that the conjugatively coupled intermediates 1 and 2 may well be described as mixed-valent diborane (II, III) species, a conclusion which is supported by the fact that related compounds with dialkylborane substituents, i.e. without complete aromatic substitution show similar effects. ${ }^{24}$

The recognition that meta disubstitution on the benzene ring disfavours spin-pairing and may thus lead to high-spin materials has prompted the synthesis of a pertinent compound 3 which exhibits corresponding magnetic properties. ${ }^{31}$ A related interesting case is the 1,8-disubstituted naphthalene 4 which shows evidence for B--B interaction due to the close proximity of the acceptor atoms. ${ }^{32}$

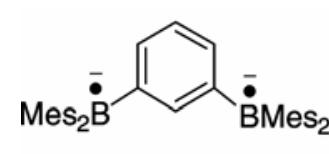

3

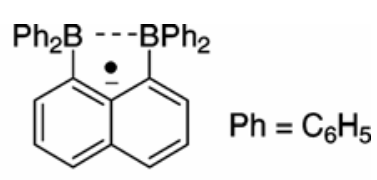

4
As in the hydrazine/hydrazinium vs aryldiamine/ aryldiaminium series the organic bridge in species like 1 or 2 can be omitted to yield directly B-B bonded diboranes which can also form stable anion radicals $\left[\mathrm{R}_{2} \mathrm{BBR}_{2}\right]^{\bullet-33}$ These intermediates with a $\mathrm{B}-\mathrm{B}$ bond order of 1.5 may be considered equivalent to the cation radicals of olefins, and the EPR hyperfine coupling of the directly connected boron atoms is strongly affected by structural factors as confirmed by crystallographic studies. ${ }^{34}$

Modification of systems $\mathbf{1}$ or $\mathbf{2}$ has been achieved by substituting the B-binding ring $\mathrm{C}$ atoms by $\mathrm{N}$ (5, 6). ${ }^{19,35}$ The charge of the radical ions then changes from $(-)$ to $(+)$ and the corresponding neutral precursors may be considered as analogues of Thiele's and Chichibabin's hydrocarbons and, replacing exocyclic $\mathrm{C}=\mathrm{C}$ by ${ }^{-} \mathrm{B}=\mathrm{N}^{+}{ }^{3}$ The spin distribution in $\mathbf{5}$ and 6 as evident from EPR and ENDOR spectroscopy ${ }^{19}$ shows that the B-N connection is not favouring spin transmission because of the large electronegativity difference and thus diminished delocalisation. Obvious manifestations of this difference are the small boron hyperfine coupling constants $<0.1 \mathrm{mT}$ and the increased spin density in the rings. ${ }^{19}$ This decreased N-B $\pi$ conjugation thus lends further support to the arguments used similarly in the discussion of the diminished aromaticity of borazines $\mathrm{B}_{3} \mathrm{~N}_{3} \mathrm{X}_{6}$. ${ }^{3,36}$

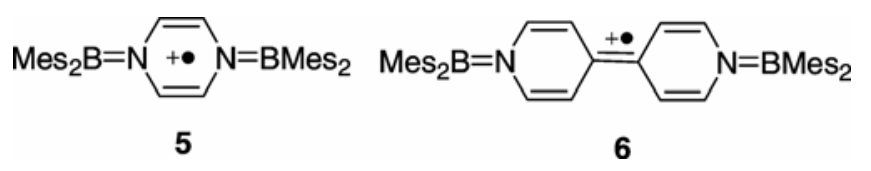

There is another, indirect mechanism by which the acceptor effect of $\mathrm{B}$ in boranes, specifically the Lewis acidity, can be exploited to stabilise radical intermediates. Coordination of $\mathrm{BX}_{3}$ molecules to Lewis basic aromatics of the pyridine type withdraws electron density and thus enhances the reducibility of the $\pi$ system as well as the stability of the radical intermediates. ${ }^{37}$ Once again, the symmetrically two-fold effect in compounds like $\mathbf{7}$ and $\mathbf{8}$ is most pronounced, the interaction between radical Lewis bases and borane Lewis acids leads to surprisingly large ${ }^{19}{ }^{10} \mathrm{~B}$ and ${ }^{11} \mathrm{~B}$ hyperfine coupling constants of about $0.25 \mathrm{mT}$ for 7 through spin polarisation, as demonstrated by EPR and heteroatom ENDOR spectroscopy. ${ }^{18}$ Like in the previously mentioned cases there are analogues for $\mathbf{7}$ and $\mathbf{8}$ in 'conventional' (i.e. non-boron) chemistry, viz. the stable radical cations formed as one-electron reduction products of the 1,4-dialkylpyrazinium ${ }^{38}$ and 4,4'-dialkyl-4,4'bipyridinium (methylviologen, 'paraquat') dications. $^{39}$

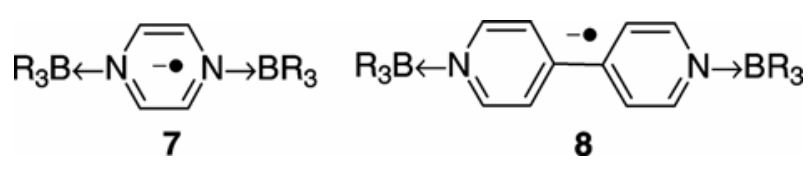

\section{Oligoborane cluster radicals $\left[B_{n} X_{n}\right]^{--}$}

In carbon-based organic chemistry, only rather few and generally unstable 'cluster' radicals with threedimensionally delocalized spin were known ${ }^{40,41}$ until the recent explosive development of the $\left(C_{\mathrm{n}}\right)^{\mathrm{k}-}$ chemistry, focussed mainly on spherical buckminsterfullerene $(n=60)$ and its reduced forms $(k=$ 1-6). ${ }^{42}$ In contrast, a number of polyhedral cluster anions $\left[\mathrm{B}_{\mathrm{n}} \mathrm{X}_{\mathrm{n}}\right]^{\bullet-}$ has been reported as early as 1966 (e.g. $\mathrm{X}=\mathrm{H}, n=8) .{ }^{43,44}$ Several theoretical studies have appeared later for species with $\mathrm{X}=\mathrm{H}^{45,46}$ and the attention was also extended to perhalide compounds 
$(\mathrm{X}=\mathrm{Hal}, \mathrm{n}=6,8,9,10),{ }^{47-56}$ to peralkylated species such as $\left[\mathrm{B}_{12} \mathrm{Me}_{12}\right]^{\bullet-57}$ and to related OR substituted derivatives $\left(\mathrm{R}=\mathrm{CH}_{2} \mathrm{Ph}, \mathrm{H}\right) .{ }^{58-60}$ The substituted 'hypercloso' compounds, typically generated by one-electron oxidation from dianionic closo precursors, are stabilized with electronegative substituents because neither $\mathrm{Hal}^{+}$nor $\mathrm{R}^{+}$or $\mathrm{RO}^{+}$are good leaving groups such as $\mathrm{H}^{+}$. Our focus here will be on the more symmetrical cases, on the compound series $\left[\mathrm{B}_{6} \mathrm{Hal}_{6}\right]^{\bullet-}\left(\mathrm{Hal}=\mathrm{Cl}, \mathrm{Br}\right.$, I), on well studied ${ }^{53-56}$ $\left[\mathrm{B}_{9} \mathrm{Br}_{9}\right]^{--}$and on the systems $\left[\mathrm{B}_{12} \mathrm{X}_{12}\right]^{\circ}$. In most cases, the number of boron nuclei and the resulting extensive hyperfine splitting precludes the observation of resolved EPR spectra, however, the $g$ factor $(h v=g \beta H)$ and its anisotropy can also provide valuable information on the electronic structure.

\section{$3.1\left[\mathrm{~B}_{6} \mathrm{Hal}_{6}\right]^{\circ}$}

The relatively small size and the potentially high (octahedral) symmetry of the clusters $\left[\mathrm{B}_{6} \mathrm{X}_{6}\right]^{k-}$ has made these systems attractive targets for theory. The closo species with $k=2$ have a molecular orbital arrangement with a doubly degenerate HOMO, ${ }^{45,46,61}$ creating an ambiguous situation with likely JahnTeller distortion on oxidation to the hypercloso form $(k=1)$. Preetz and coworkers have managed to synthesise, isolate and structurally characterise deeply coloured species like $\left[\mathrm{B}_{6} \mathrm{I}_{6}\right]^{\bullet-}$ which show relatively small signs of cluster distortion in addition to counterion and packing effects. ${ }^{47,48}$ Slight trigonal distortions of the octahedral framework were calculated by DFT for all monoanions $\left[\mathrm{B}_{6} \mathrm{X}_{6}\right]^{\bullet-}, \mathrm{X}=\mathrm{Cl}, \mathrm{Br}, \mathrm{I}^{27}$

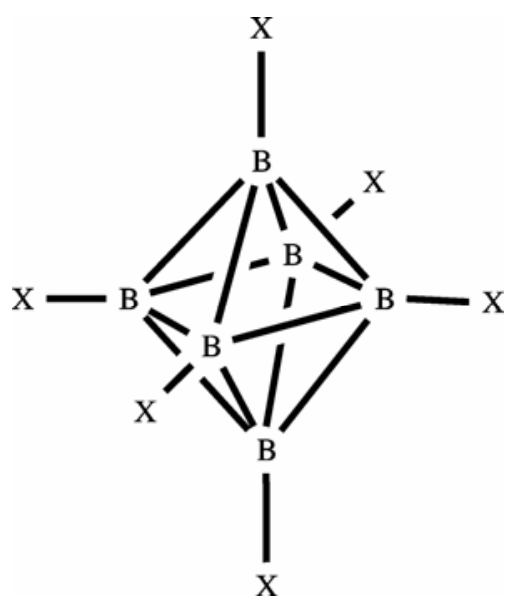

The unusual electronic structure of these species is evident from EPR spectroscopy. ${ }^{49}$ Very rapid relaxation due to the presence of excited states lying close to the doublet ground state results in severe line broadening which is particularly pronounced in the presence of the heavier halogens with their large spin-orbit coupling constants; the signal of $\left[\mathrm{B}_{6} \mathrm{I}_{6}\right]^{\bullet-}$ could thus be observed only at $4 \mathrm{~K}$. The line broadening and the large number of hyperfine lines expected for the coupling of the unpaired electron with six boron and six nuclear spin-active halide nuclei in the combinations $\left({ }^{35} \mathrm{Cl},{ }^{37} \mathrm{Cl} ;{ }^{79} \mathrm{Br},{ }^{81} \mathrm{Br} ;{ }^{127} \mathrm{I}\right)$ given by their natural abundances precluded the observation of electron-nuclear hyperfine splitting by EPR. However, the close-lying excited states resulting from the partially occupied degenerate $\operatorname{Mos}^{27,45,46,49}$ are also responsible for the shift of the $g$ tensor components to rather low values, an effect which is further enhanced by the spin-orbit coupling of the significantly participating halogen atoms. ${ }^{49}$ In fact, DFT calculations have reasonably reproduced the extraordinary experimental EPR $g$ anisotropy of $g_{1}=2.04, g_{2}=1.66, g_{3}=1.15$, and indicated a wellaveraged spin distribution of about $1 / 12$ for each of the $\mathrm{B}$ and $\mathrm{I}$ atoms in $\left[\mathrm{B}_{6} \mathrm{I}_{6}\right]^{-2}{ }^{-27}$ With the lighter halogen substituents $\mathrm{Br}$ and $\mathrm{Cl}$ the $g$ anisotropy is less pronounced, ${ }^{49,50}$ not only due to the much smaller spin-orbit coupling constants of these atoms but also because of diminished spin transfer to the peripheral halides (e.g. $4.5 \%$ to $\mathrm{Cl}$ instead of $8.4 \%$ to I) ${ }^{27}$

The variation of halides from $\mathrm{I}$ via $\mathrm{Br}$ to $\mathrm{Cl}$ and the investigation of mixed derivatives $\left[\mathrm{B}_{6} \mathrm{Hal}_{n} \mathrm{Hal}^{\prime}{ }_{6-n}\right]^{\circ-}$ in isomeric forms (cis, trans) as well as halide/ hydride and halide/alkyl species has thus experimentally confirmed ${ }^{49,50}$ the essential contributions from the substituents to the singly occupied cluster orbital. The strong substituent effect is surprising at first, considering the high electronegativity difference between halogen and boron atoms. However, free electron pairs of the halide substituents are involved in the spin accommodation as confirmed by the calculations for $\left[\mathrm{B}_{6} \mathrm{I}_{6}\right]^{\circ-}$. ${ }^{27}$

While fluoride substituents created a synthetic problem in the series $\left[\mathrm{B}_{6} \mathrm{Hal}_{6}\right]^{\circ-}$, there have been a few radicals reported ${ }^{62}$ with the $\mathrm{BF}$ group (which is isoelectronic to $\mathrm{CO}$ !).

\section{$3.2 \quad\left[B_{9} B r_{9}\right]^{\circ}$}

The tricapped trigonal prismatic closo cluster system $\left[\mathrm{B}_{9} \mathrm{Br}_{9}\right]^{k-}, k=0-2$, has been well-characterised experimentally and theoretically, its chemical and electrochemical two-step electron transfer reactivity 
with a $\left[\mathrm{B}_{9} \mathrm{Br}_{9}\right]^{\bullet-}$ intermediate has been described ${ }^{53-55}$ as well as the effects of protonation. ${ }^{56}$ The lower symmetry in comparison to $\left[\mathrm{B}_{6} \mathrm{X}_{6}\right]^{\bullet-}$ and $\left[\mathrm{B}_{12} \mathrm{X}_{12}\right]^{\bullet-}$ results in a non-degenerate redox active MO (HOMO of $\left[\mathrm{B}_{9} \mathrm{X}_{9}\right]^{2-}$ ) which is responsible for less pronounced $g$ factor anisotropy ${ }^{55}$ for $\left[\mathrm{B}_{9} \mathrm{Br}_{9}\right]^{\bullet-}(g>2$, $\left.g_{1}-g_{3}=0.05\right)$ in relation to $\left[\mathrm{B}_{6} \mathrm{Br}_{6}\right]^{\bullet-}\left(g<2, g_{1}-g_{3}=\right.$ $0 \cdot 20)$. Structural changes during the electron transfer are rather small, the overall tricapped trigonal prismatic cluster arrangement being maintained. ${ }^{55}$ This obviously low reorganisation energy probably contributes to the stability of the radical intermediate in that redox system. ${ }^{54,55}$

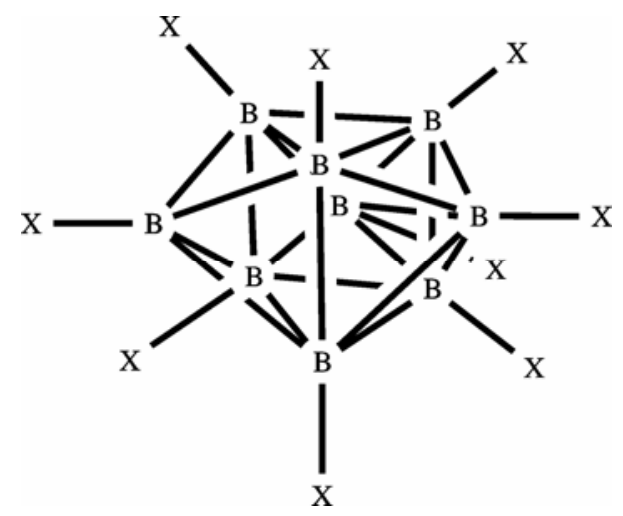

\section{$3.3\left[B_{12} X_{12}\right]^{\circ}$}

Icosahedral closo- $\left[\mathrm{B}_{12} \mathrm{X}_{12}\right]^{2-}$ ions are prototypical polyborane clusters with high stability ${ }^{15}$ and ' $3 \mathrm{D}$ aromaticity ${ }^{69,70}$ Similarly as for $\left[\mathrm{B}_{6} \mathrm{X}_{6}\right]^{2-}$, the high symmetry results in a degenerate $\mathrm{HOMO}^{45,46}$ Although the oxidation of $\left[\mathrm{B}_{12} \mathrm{X}_{12}\right]^{2-}(\mathrm{X}=\mathrm{Hal})$ via radical anion intermediates $\left[\mathrm{B}_{12} \mathrm{X}_{12}\right]^{\bullet-}$ has been considered, ${ }^{46,63}$ this process is highly irreversible in electrochemical experiments even at low temperatures. UV Irradiation in an EPR cavity produces signals with relatively small $g$ anisotropy in the frozen state, they were tentatively attributed to distorted $\left[\mathrm{B}_{12} \mathrm{X}_{11}\right]^{\bullet 2-}(\mathrm{X}=\mathrm{Br}, \mathrm{I})$ due to the formation of $\mathrm{X}_{2}$ on prolonged irradiation. For non-halide substituted derivatives there were several recent reports by Hawthorne and coworkers describing isolated, slightly Jahn-Teller distorted hypercloso species $\left[\mathrm{B}_{12} \mathrm{Me}_{12}\right]^{\circ}$ $(g=2.0076)$ and purple $\left[\mathrm{B}_{12}(\mathrm{OR})_{12}\right]^{\bullet-}, \mathrm{R}=\mathrm{CH}_{2} \mathrm{Ph}$ and other alkyl groups. ${ }^{57-59}$ Back-bonding from the electron rich and lone pair-providing alkoxy groups to the electron deficient $\mathrm{B}_{12}$ cluster was postulated, based on the structural changes such as shrinking $\mathrm{B}-\mathrm{O}$ distances on oxidation. ${ }^{58}$ The alkoxo derivatives were labelled as discrete nanomolecular ions with tunable pseudometallic properties such as metal-like redox reactions ${ }^{59}$ while the stable green ion $\left[\mathrm{B}_{12}(\mathrm{OH})_{12}\right]^{\bullet-}$ was structurally analyzed as the $\mathrm{Cs}^{+}$salt, and characterized by EPR $(g=2 \cdot 0042){ }^{60}$

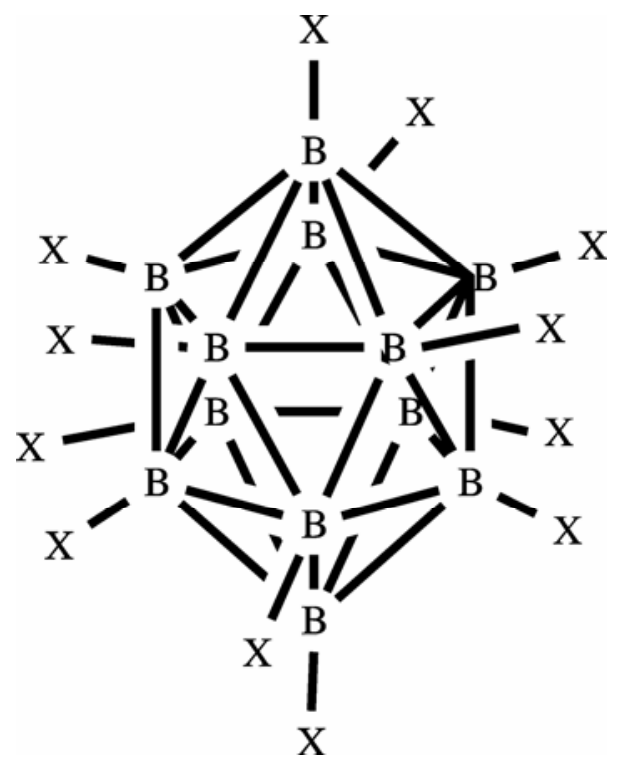

\section{Carborane cluster radicals}

Starting from $\left[\mathrm{B}_{12} \mathrm{R}_{12}\right]^{\bullet-}$, the formal replacement of one $\mathrm{BR}$ by an equivalent $[\mathrm{CR}]^{+}$function not only removes the symmetry and thus the orbital degeneracy, it also changes the redox potential and leaves a neutral radical species such as $\left[\mathrm{CB}_{11} \mathrm{Me}_{12}\right]^{\circ-}$ $(g=2.0037)$ as described by Michl and coworkers. ${ }^{64}$

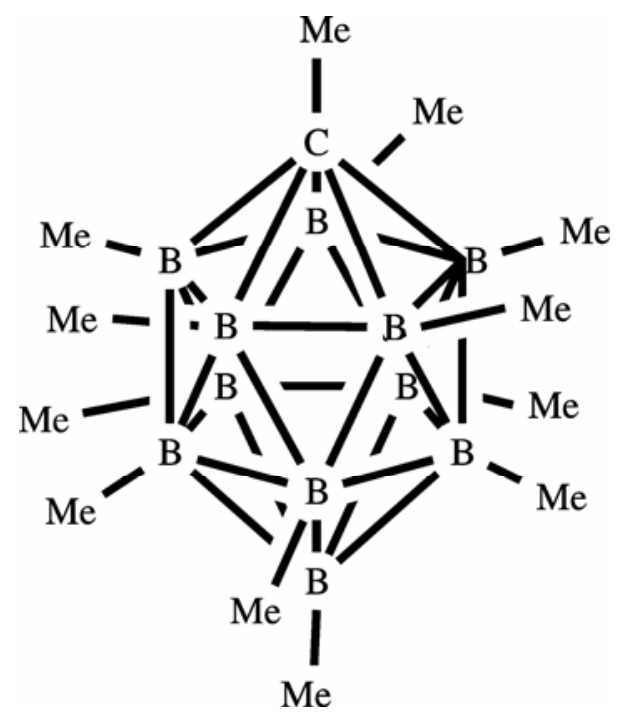

Compound $\left[\mathrm{CB}_{11} \mathrm{Me}_{12}\right]^{\bullet-}$ has been discussed in connection with its synthetic potential as an oxidant, ${ }^{64}$ whereas related anion radical species [1,2- 
$\left.\mathrm{Ph}_{2}-1,2-\mathrm{C}_{2} \mathrm{~B}_{10} \mathrm{H}_{10}\right]^{\bullet-}$ and $\left[1,2-\left(\mathrm{CH}_{2}\right)_{3}-1,2-\mathrm{C}_{2} \mathrm{~B}_{11} \mathrm{H}_{11}\right]^{\bullet}$ have been reported recently. ${ }^{65,66}$

Higher symmetry was established EPR spectroscopically for the $\left[\mathrm{C}_{4} \mathrm{~B}_{8} \mathrm{R}_{4} \mathrm{H}_{8}\right]^{\circ-}$ radical ion $(\mathrm{R}=$ $\left.\mathrm{SiMe}_{3}\right)^{67}$ which was obtained by reduction of the cuboctahedral precursor. ${ }^{68}$ An unusually well-resolved EPR spectrum $(g=2.0030)$ shows large ${ }^{11} \mathrm{~B}$ hyperfine splitting of $1.165 \mathrm{mT}\left(\mathrm{a}\left({ }^{10} \mathrm{~B}\right)=0.390 \mathrm{mT}\right)$ with only four equivalent $\mathrm{B}$ atoms. ${ }^{68}$ The underlying electronic structure has been assessed through DFT calculations for $\left[\mathrm{C}_{4} \mathrm{~B}_{8} \mathrm{H}_{12}\right]^{\bullet}$, which gave spin densities of $7.7 \%$ for each of the carbon atoms, $20.3 \%$ for the separated boron atoms on top and bottom of the cluster, and $0.00 \%$ for the central four B atoms which lie in a nodal plane of the singly occupied molecular orbital (SOMO). In spite of the threedimensional spin distribution, the unpaired electron is thus not evenly delocalized but concentrated in two spatially separated regions of the molecule.

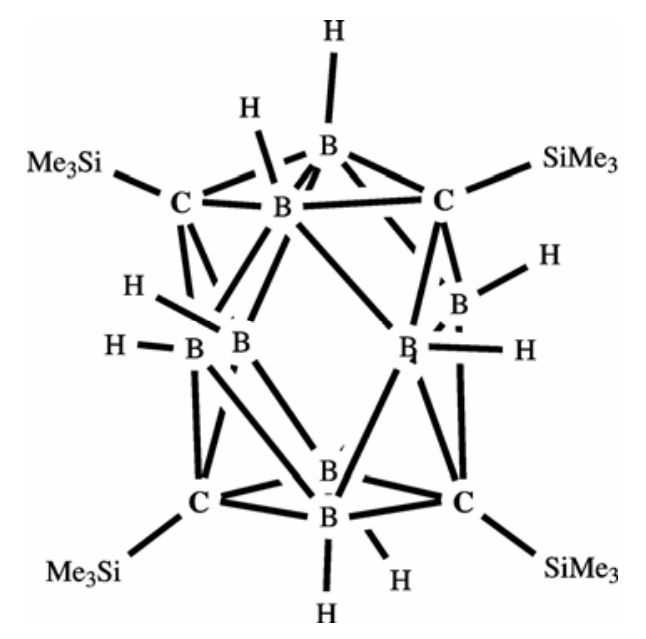

\section{Perspectives on B-containing spin carriers}

The examples presented here demonstrate that twoand three-dimensional spin accommodation is possible in stable radicals containing boron as essential constituents. From merely borane-stabilised oneelectron reduced organic $\pi$ systems via boroncentered $\pi$ radicals with formal mixed valency of B after single spin injection leads a way to halide-, alkyl-, alkoxy- or trialkylsilyl-substituted polyborane and carborane clusters in which the unpaired electron is distributed three-dimensionally over the cluster framework and the substituents.

The '3D aromaticity" ${ }^{69,70}$ of borane clusters as stabilized by certain rules ${ }^{15}$ justifies the extension to the theoretically and experimentally established 3D spin delocalization, a move beyond the confine- ments of the otherwise so successful concept of $\pi$ radical stability. Various aspects of EPR and ENDOR spectroscopy can be employed to analyse the spin distribution, and modern DFT methods now allow a confident assessment of the electronic structure. Still, the application of isoelectronic relationships can guide in finding suitable paramagnetic structures. Considering the results summarized here and the wide use of $\mathrm{N}$ and $\mathrm{O}$ heteroatoms in redoxand spin-active components for e.g. molecular magnets or sensors it is apparent that boron-containing materials ${ }^{1,10,25}$ are also a viable and attractive option, as suggested by recent calculations on borafullerenes like $\mathrm{B}_{80}$ or $\mathrm{B}_{84 .}{ }^{4}$ There is clearly a wide research field open for boron-based spin carrying systems, and this article has demonstrated various strategies to obtain such materials.

\section{Carborane-appended carbon nanotubes}

Carbon nanotubes (CNTs) are allotropes of carbon that take the form of a cylindrical arrangement of carbon atoms. Carbon nanotubes are either singlewall (SWCNT) or multi-wall (MWCNT). Since their discovery in $1991,{ }^{71}$ CNTs have attracted wide attention with numerous applications proposed for them. ${ }^{72}$ CNTs possess the unique property of being able to enter various cells without showing apparent toxic effects. For instance, it has been reported that peptide-functionalised single-walled carbon nanotubes (SWCNTs) were able to cross cell membranes and concentrate in the cytoplasm of 3T6, 3T3 fibroblasts and phagocytic cells, without causing their death or inflicting other damages. ${ }^{73}$ Similar results were obtained in HL60 cells, where it was found that functionalised SWCNTs can help to transport large attached groups into cells without themselves exhibiting cell toxicity. ${ }^{74}$ In vitro studies of folic acid and fluorescent tag-conjugated SWCNTs have shown them to be effective in targeting HeLa cells, which are rich in folic acid receptors and are thought to stem from cervical cancer. ${ }^{75}$ The stability and flexibility of carbon nanotubes is likely to prolong the circulation time and the bioavailability of these macromolecules, thus enabling highly effective gene and drug therapies. The reports of enhanced water solubility of CNTs through side-wall derivatisation with biologically important moieties ${ }^{76-93}$ caused us to explore the feasibility of using suitably derived SWCNTs as boron delivery agents for use in BNCT. $^{94}$ We have successfully attached nido- 
carborane units to the side walls of single-wall carbon nanotubes to produce high boron-content and water soluble SWCNTs (figure 1). ${ }^{94}$ These were then used to treat mice bearing the EMT6 tumour cells, a mammary carcinoma. A favourable tumourto-blood ratio of 3.12 and a boron concentration of $21.5 \mu \mathrm{g} / \mathrm{g}$ tumour were obtained after $48 \mathrm{~h}$ of administration. In addition, it was observed that retention in tumour tissue was higher than in the blood and other tissues including lung, liver and spleen. Although the initial results were good enough for a possibly successful BNCT trial, current research is involved in modifications to improve both the selectivity and boron concentration.

In addition to side wall attachments, it is possible to encapsulate boron carriers in the empty cavities of CNTs. ${ }^{95}$ In this regard, it has been reported that ortho-carboranes were successfully encapsulated inside SWCNTs. ${ }^{96}$ If high yield methods could be developed for producing this material, it could develop into an effective carrier for BNCT treatment. Overall, the use of carbon nanotubes in the future generations of BNCT drug delivery systems may improve therapeutic effectiveness and decrease undesirable side effects. Nevertheless, the long-term toxicity of carbon nanotubes must be completely assessed. Further research is also expected to fully reveal the mechanisms of transport across cell membranes. Other issues to be addressed include devising cheap, large-scale methods and techniques to embed small drug molecules, proteins, peptides and genes inside and onto carbon nanotubes.

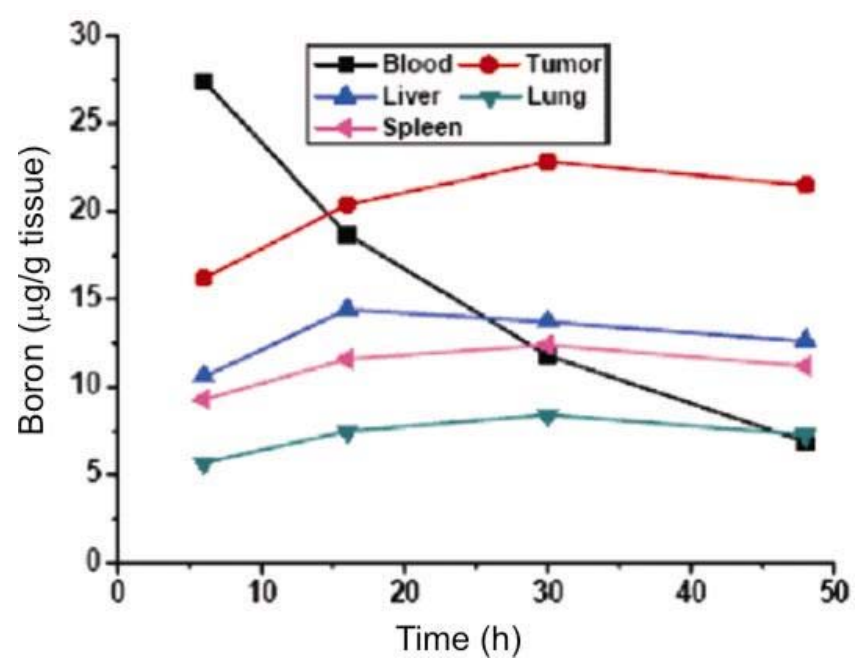

Figure 1. Distributions of boron in saline in different tissues. $^{94}$

\section{Boron nanotubes}

Another suggested nanomaterial for use as a BNCT agent is the boron nanotube (BNT). Boron nanotubes are one of the latest nanomaterials resulting from the advancement in nanotechnology. Interest in their fabrication is largely due to the variable conductivity limitations present in the well-documented carbon nanotubes. The boron nanotubes can lead to the creation of a series of boron nanostructures, such as boron nanoribbons ${ }^{97}$ and nanowires (figure 2).$^{98}$

The first successful synthesis of a single-wall boron nanotube was reported quite recently by Ciuparu et $a l .{ }^{99}$ They managed to produce nanotubes with diameters of approximately $3 \mathrm{~nm}$ and lengths of $16 \mathrm{~nm}$. However, these novel boron nanotubes were found to be highly sensitive to high energy electron beams and hence detailed structural characteristics could not be determined. Nevertheless, this encouraging breakthrough has increased the interest in boron nanotubes. For instance, a recent study by Kuntsmann et al. found new forms of radially constricted, single-wall, zigzag boron nanotubes which may serve as intermediates in the formation of an ideal nanotubular system. ${ }^{100}$

Although boron nanotubes have the potential to be ideal BNCT agents, there remain many issues that need to be addressed before boron nanotubes can be applied to the realm of drug delivery. The major challenges would be in the large scale fabrication of boron nanotubes and in developing strategies to make boron nanotubes water soluble. At present, most of the research work is focused on uncovering the characteristics of boron nanotubes and coming up with probable applications. ${ }^{101}$ It might not be long before boron nanotubes can be engaged in drug delivery.

\section{Magnetic nanoparticles}

It is well-known that one of the biggest obstacles in chemotherapy and drug discovery is that most of the compounds are relatively non-specific. When therapeutic drugs are infused intravenously, the drug will generally distribute in and attack both tumourous and healthy cells, which results in deleterious sideeffects. In magnetically targeted therapy (figure 3), a drug is attached to a biocompatible magnetic nanoparticle carrier, usually in the form of a biocompatible ferrofluid, and is injected into the patient via the circulatory system. When these particles 

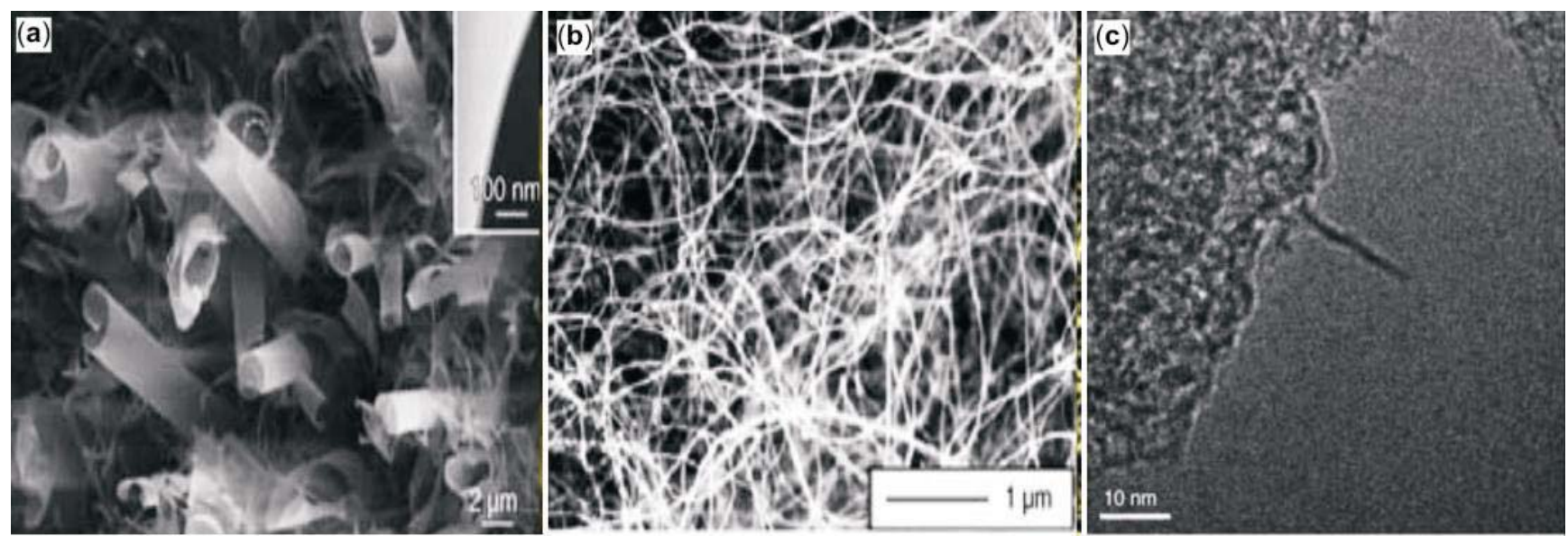

Figure 2. SEM micrographs ${ }^{101}$ (a) Boron nanoribbons. (b) Boron nanowires. (c) Boron nanotubes.

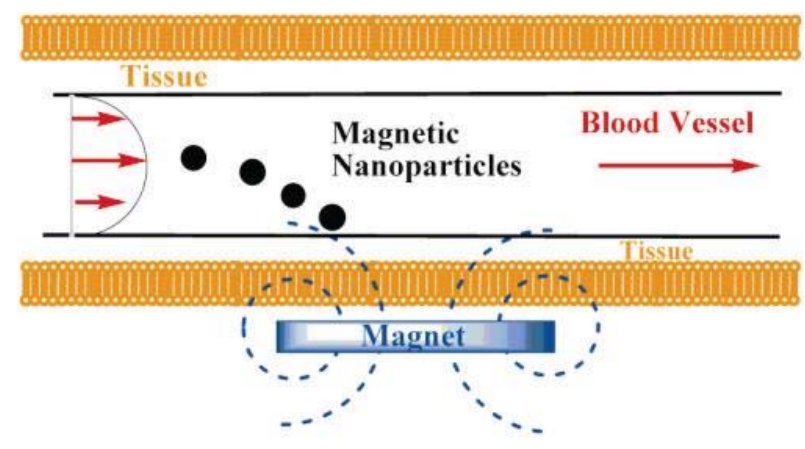

Figure 3. Magnetic drug delivery mechanism.

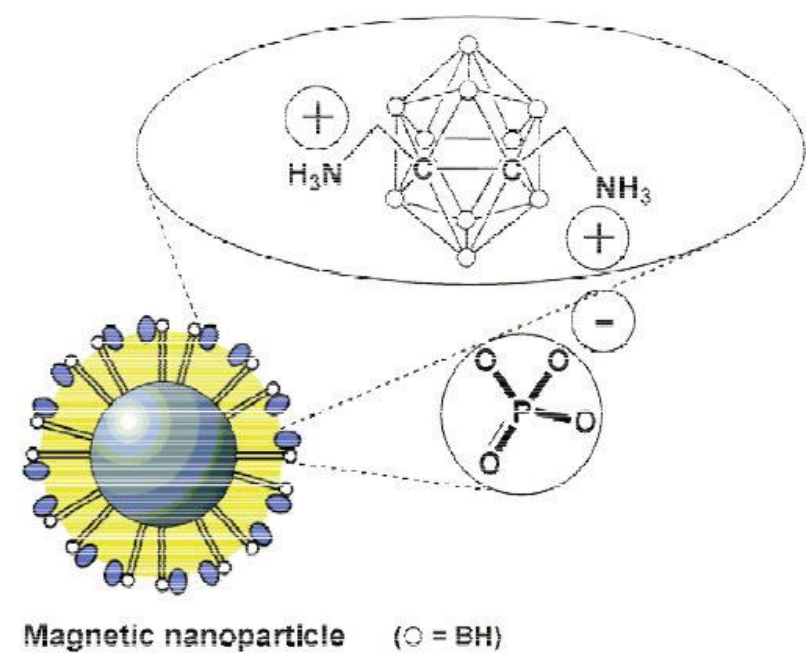

Figure 4. Magnetic nanoparticles as BNCT carriers.

enter the blood stream, external high-gradient magnetic fields can be used to concentrate the complex at a specific target site within the body. Once the $\mathrm{drug} /$ carrier is correctly concentrated, the drug can be released, either via enzymatic activity or changes in physiological conditions, and be taken up by the tumour cells. ${ }^{102}$ The advantage of the methodology consists in the decrease of the required amount of the cytotoxic drugs, thus reducing the associated side effects. This technique has been examined as a means to target cytotoxic drugs to brain tumours. Studies have demonstrated that particles as large as 1-2 $\mu \mathrm{m}$ could be concentrated at the site of intracerebral rat glima-2 (RG-2) tumours; a later study demonstrated that $10-20 \mathrm{~nm}$ magnetic particles were even more effective at targeting these tumours in rats. ${ }^{103,104}$ Studies of magnetic targeting in humans demonstrated that the infusion of ferrofluids was well tolerated in most of the patients, and that the ferrofluid could be successfully directed to advanced sarcomas without associated organ toxicity. In addition, the pre-clinical and experimental results indicated that it is possible to overcome the limitations associated with magnetically targeted drug delivery, such as the possibility of embolization of the blood vessels in the target region due to accumulation of the magnetic carriers, etc. ${ }^{105} \mathrm{Stu}-$ dies of magnetic targeting is one of the most active areas of drug delivery research. ${ }^{106-108}$ Recently, FeRx Inc. was granted fast-track status to proceed with multi-centre Phase I and II clinical trials of their magnetic targeting system for liver tumours. Application of this technique can therefore be considered appropriate for the use in BNCT treatment.

Recently, we have successfully immobilized carboranyl dual-chain ammonium salts ${ }^{109}$ onto modified magnetic nanoparticles in high loading amounts via the electrostatic interaction between negatively charged phosphate groups on the surface of magnetic nanoparticles and $-\mathrm{NH}_{3}^{+}$groups on the carbo- 
rane cages (figure 4). The cellular uptake of this potential BNCT agent is presently undergoing studies in our laboratories. ${ }^{110}$

This research is just in its initial stages and issues related to magnetic nanoparticles, such as control of particle size, surface functionalisation, and environmental compatibility need to be resolved.

\section{Acknowledgements}

We thank Deutsche Forschungsgemeinschaft, Fonds der Chemischen Industrie, Land Baden-Württemberg (to WK), National Science Foundation, Grant No. CHE-0906179 to NSH for continued research funding. In addition, we acknowledge particularly the support from the Alexander von Humboldt Foundation (to NSH) for scientific collaboration.

\section{References}

1. Jemmis E D and Jayasree E G 2003 Acc. Chem. Res. 36816

2. Power P P 2003 Chem. Rev. 103789

3. Liu Z and Marder T B 2008 Angew. Chem. Int. Ed. 47242

4. Szwacki N G, Sadrzadeh A and Yakobson B I 2007 Phys. Rev. Lett. 98166804

5. Vinu A, Anandan S, Anad C, Srinivasu P, Ariga K and Mori T 2008 Mic. Meso. Mater. 109398

6. Nagamatsu J, Nakagawa N, Muranaka T, Zenitani Y and Akimitsu J 2001 Nature 41063

7. Köhler J 2001 Angew. Chem. 113 2501; Angew. Chem. Int. Ed. $\mathbf{4 0} 2435$

8. Giles J R M and Roberts B P $1983 \mathrm{~J}$. Chem. Soc. Perkin Trans. 743

9. Kaim W 1981 Chem. Ber. 1143789

10. Elbing M and Bazan G C 2008 Angew. Chem. Int. Ed. 47834

11. Liu Y, Xu X, Zheng F and Cui Y 2008 Angew. Chem. Int. Ed. $\mathbf{4 7} 4538$

12. Kaim W, Hosmane N S, Zalis S, Maguire J A and Lipscomb W N 2009 Angew. Chem. Int Ed. 485082

13. Bock H and Fuss W 1971 Z. Naturforsch., Teil B26 525

14. Schulz A and Kaim W 1989 Chem. Ber. 1221863

15. Hoffmann R and Lipscomb W N 1962 J. Chem. Phys. 362179

16. Yamamoto $\mathrm{T}$, Nakai $\mathrm{K}$ and Matsumura A 2008 Cancer Lett. 262143

17. Bock H, Kaim W, Semkow A and Nöth H $1980 \mathrm{~J}$. Am. Chem. Soc. 1024421

18. Kaim W and Lubitz W 1983 Angew. Chem. 95 915; Kaim W and Lubitz W 1983 Angew. Chem. Int. Ed. Engl. 22 892; Kaim W and Lubitz W 1983 Angew. Chem. Suppl. 1209

19. Lichtblau A, Kaim W, Schulz A and Stahl T 1992 J. Chem. Soc., Perkin Trans. 21497
20. Eisch J J, Dluzniewski T and Behrooz M 1993 Heteroat. Chem. 4235

21. Griffin R G and van Willigen H $1972 \mathrm{~J}$. Chem. Phys. 572285

22. Olmstead M M and Power P P $1086 \mathrm{~J}$. Am. Chem. Soc. 1084235

23. Cummings S A, Iimura M, Harlan C J, Kwaan R J, Trieu I V, Norton J R, Bridgewater B M, Jäkle F, Sundararaman A and Tilset M 2006 Organoemetallics 251565

24. Kaim W and Schulz A 1984 Angew. Chem. Int. Ed. Engl. 23615

25. Yuan Z, Collings J C, Taylor N J, Marder T B, Jardin C and Halet J-F $2000 \mathrm{~J}$. Solid State Chem. 1545

26. Pan J-H, Chou Y-M, Chiu H-L and Wang B-C 2007 J. Phys. Org. Chem. 20743

27. Zalis S and Kaim W 2007 Main Group Chem. 6267

28. Robin M B and Day P 1967 Adv. Inorg. Chem. Radiochem. 10247

29. (a) Richardson D E and Taube H 1984 Coord. Chem. Rev. 60 107; (b) Kaim W and Lahiri G K 2007 Angew. Chem. 119 1808; Angew. Chem. Int. Ed. 46 1778; (c) Kaim W and B. Sarkar B 2007 Coord. Chem. Rev. 251584

30. (a) Lambert C, Nöll G and Schelter J 2002 Nature Mat. 1 69; (b) Bonvoisin J, Launay J-P, Rovira C and Veciana J 1994 Angew. Chem. Int. Ed. Engl. 33 2106

31. Rajca A, Rajca S and Desai S R 1995 Chem. Commun. 25

32. Hoefelmeier J D and Gabbai F P $2000 \mathrm{~J}$. Am. Chem. Soc. 1229054

33. Klusik H and Berndt A 1982 J. Organomet. Chem. $232 \mathrm{C} 21$

34. Grigsby W J and Power P P 1997 Chem. Eur. J. 3 368

35. Lichtblau A, Hausen H-D, Schwarz W and Kaim W 1993 Inorg. Chem. 3273

36. Abbey E R, Zakharov L N and Liu S-Y $2008 \mathrm{~J}$. Am. Chem. Soc. 1307250

37. Kaim W 1994 Top. Curr. Chem. 169231

38. Hausen H-D, Schulz A and Kaim W 1988 Chem. Ber. 1212059

39. Summers L A 1980 The bipyridinium herbicides (London: Academic Press)

40. Fossey J, Lefort D and Sorba J 1995 Free radicals in organic chemistry (New York: Wiley)

41. von Ragué Schleyer P 2005 Chem. Rev. 1053433

42. Kadish K M and Ruoff R S 2000 Fullerenes: Chemistry, physics, and technology (New York: Wiley)

43. Lewis J S and Kaczmarczyk A $1966 \mathrm{~J}$. Am. Chem. Soc. 881068

44. Klanberg F, Eaton D R, GuggenbergerL J and Muetterties E L 1967 Inorg. Chem. 61271

45. McKee M L, Wang Z-X and von Ragué Schleyer $P$ 2000 J. Am. Chem. Soc. 1224781

46. McKee M L 2002 Inorg. Chem. 411299

47. Heinrich A, Keller H-L and Preetz W 1990 Z. Naturforsch. B45 184

48. Lorenzen V and Preetz W 1997 Z. Naturforsch. 52 565 
49. Lorenzen V, Preetz W, Baumann F and Kaim W 1998 Inorg. Chem. 374011

50. Wanner M, Kaim W, Lorenzen V and Preetz W 1999 Z. Naturforsch. B54 1103

51. Speiser B, Wizemann T and Wuerde M 2003 Inorg. Chem. 424018

52. Einholz W, Vaas K, Wieloch C, Speiser B, Wizemann T, Stroebele M and Meyer H-J 2002 Z. Anorg. Allg. Chem. 628258

53. Wong E H and Kabbani R M 1981 Inorg. Chem. 19 451

54. Speiser B, Tittel C, Einholz W and Schäfer R 1999 Dalton Trans. 1741

55. Binder H, Kellner R, Vaas K, Hein M, Baumann F, Wanner M, Winter R, Kaim W, Hönle W, Grin Y, Wedig U, Schultheiss M, Kremer R K, von Schnering $\mathrm{H} \mathrm{G}$, Groeger O and Engelhardt G 1999 Z. Anorg. Allg. Chem. 6251059

56. Binder H, Kellner R, Vaas K, Hein M, Baumann F, Wanner M, Kaim W, Wedig U, Hönle W, von Schnering H G, Groeger O and Engelhardt G 1999 Z. Anorg. Allg. Chem. 6251638

57. Peymann T, Knobler C B, Khan S I and Hawthorne M F 2001 Inorg. Chem. 401291

58. Farha O K, Julius R L, Lee M W, Huertas R E, Knobler C B and Hawthorne M F $2005 \mathrm{~J}$. Am. Chem. Soc. 12718243

59. Lee W W, Farha O K, Hawthorne M F and Hansch C H 2007 Angew. Chem. Int. Ed. 463018

60. Van N-D, Tiritiris I, Schleid Th, Sarkar B, Kaim W and Winter R (to be submitted)

61. Fowler P W 1986 J. Chem. Soc., Faraday Trans. 2 8261

62. Kaim W, Bock H, Hawker P and Timms P L $1980 \mathrm{~J}$. Chem. Soc. Chem. Commun. 577

63. Volkov O and Paetzold P 2006 Z. Anorg. Allg. Chem. 632945

64. King B T, Noll B C, McKinley A J and Mich J 1996 J. Am. Chem. Soc. 11810902

65. Fox M A, Nervi C, Crivello A and Low P J 2007 Chem. Commun. 2372

66. Fu X, Chan H-S and Xie Z 2007 J. Am. Chem. Soc. 1298964

67. Hosmane N S, Zhang H, Maguire J A, Wang Y, Demissie T, Colacort T J, Ezhova M B, Lu K-J, Zhu D, Gray T G, Helfert S C, Hosmane S N, Collins J D, Baumann F, Kaim W and Lipscomb W N 2000 Organometallics 19497

68. Hosmane N S, Zhang H, Maguire J A, Wang Y, Colacot T J and Gray T G 1996 Angew. Chem., Int. Ed. Engl. 351000

69. Lipscomb W N, Pitochelli A R and Hawthorne M F $1959 \mathrm{~J}$. Am. Chem. Soc. 815833

70. Chen Z and King R B 2005 Chem. Rev. 1053613

71. Iijma S 1991 Nature 35456

72. Cuenca A, Jiang H, Hochwald S, Delano M, Cance W and Grobmyer S 2006 Cancer 107459

73. Pantarotto D, Briand J P, Prato M and Bianco A 2004 Chem. Commun. 116

74. Cherukuri P, Bachilo S M, Litovsky S H and Weisman R B $2004 \mathrm{~J}$. Am. Chem. Soc. 12615638
75. Kam N W, O'Connell M, Wisdom J A and Dai H 2005 Proc. Natl. Acad. Sci. USA 10211600

76. Pantarotto D, Partidos C D, Graff R, Hoebeke J, Briand J-P, Prato M and Bianco A $2003 \mathrm{~J}$. Am. Chem. Soc. 1256160

77. Kam N WS, Jessop T C, Wender P A and Dai H 2004 J. Am. Chem. Soc. 1266850

78. Furtado C A, Kim U J, Gutierrez H R, Pan L, Dickey E C and Eklund P C $2004 \mathrm{~J}$. Am. Chem. Soc. 1266095

79. $\mathrm{Hu} \mathrm{H}, \mathrm{Ni} \mathrm{Y}$, Montana V, Haddon R C and Parpura V 2004 Nano Lett. 4507

80. Georgakilas V, Tagmatarchis N, Pantarotto D, Bianco A, Briand J P and Prato M 2002 Chem. Commun. 243050

81. Fu K, Li H, Zhou B, Kitaygorodskiy A, Allard L F and Sun Y P $2004 \mathrm{~J}$. Am. Chem. Soc. 1264669

82. Georgakilas V, Kordatos K, Prato M, Guldi D M, Holzinger M and Hirsch A $2002 \mathrm{~J}$. Am. Chem. Soc. 124760

83. Guldi D M, Marcaccio M, Paolucci D, Paolucci F, Tagmatarchis N, Tasis D, Vazquez E and Prato M 2003 Angew. Chem. Int. Ed. 424206

84. Holzinger M, Abraham J, Whelan P, Graupner, R, Ley, L, Hennrich F, Kappes M and Hirsch A $2003 \mathrm{~J}$. Am. Chem. Soc. 1258566

85. Sun Y P, Huang W, Lin Y, Fu K, Kitaygorodskiy A, Riddle L A, Yu Y J and Carroll D L 2001 Chem. Mater. 132864

86. Peng H, Alemany L B, Margrave J L and Khabashesku V N 2003 J. Am. Chem. Soc. 12515174

87. Peng H, Reverdy P, Khabashesku V N and Margrave J L 2003 Chem. Commun. 3362

88. Huang W, Fernando S, Lin Y, Zhou B, Allard L F and Sun Y P 2003 Langmuir 197084

89. Dyke C A and Tour J M 2003 Nano Lett. 31215

90. Zhu W, Minami N, Kazaoui S and Kim Y. 2003 J. Mater. Chem. 132196

91. Umek P, Seo J W, Hernadi K, Mrzel A, Pechy Peter, Mihailovic D D and Forro L 2003 Chem. Mater. 154751

92. Hu H, Zhao B, Hamon M A, Kamaras K, Itkis M E and Haddon R C 2003 J. Am. Chem. Soc. 12514893

93. Chen R J, Choi H C, Bangsaruntip S, Yenilmez E, Tang X, Wang Q, Chang Y-L and Dai H $2004 J$. Am. Chem. Soc. 1261563

94. Zhu Y H, Ang T P, Carpenter K, Maguire J, Hosmane N and Takagaki M.2005 J. Am. Chem. Soc. 1279875

95. Dai H 2002 Acc. Chem. Res. 351035

96. Morgan D A, Sloan J and Green M L H 2002 Chem. Commun. 202442

97. Xu T, Zheng J G, Wu N, Nicholls A, Roth J R, Dikin D A and Ruoff R S 2004 Nano Lett. 4 963

98. Cao L M, Tian H, Zhang Z, Zhang X Y, Gao C X and Wang W K 2004 Nanotechnology 15139

99. Ciuparu D, Klie R, Zhu Y and Pfefferle L 2004 J. Phys. Chem. 1083967

100. Kuntsmann J and Quandt A 2005 Chem. Phys. Lett. 40221 
101. Quandt A and Boustani I 2005 Chem. Phys. Chem. 6 2001

102. Alexiou C, Arnold W, Klein R J, Parak F G, Hulin $\mathrm{P}$, Bergemann $\mathrm{C}$, Erhardt W, Wagenpfeil $\mathrm{S}$ and Lübbe A S 2000 Cancer Res. 606641

103. Pulfer S K, Ciccotto S L and Gallo J M $1999 \mathrm{~J}$. Neuro-Oncol. 4199

104. Sincai M, Ganga D, Ganga M, Argherie D and Bica D 2005 J. Magn. Magn. Mater. 293438

105. Gallo J M and Hafeli U 1997 Cancer Res. 57 3063
106. Veyret R, Delair T and Elaissari A 2005 J. Magn. Magn. Mater. 293171

107. Sang J S, Reichel J, Bo H, Schuchman M and Sang B L 2005 J. Am. Chem. Soc. 1277316

108. Zebli B, Susha A S, Sukhorukov G B, Rogach A L and Parak W J 2005 Langmuir 214262

109. Zhu Y H Bis(aminoalkyl)-dicarbaborane derived boron neutral capture therapy drugs, US Patent Application number 60/737,827, filed on 17 November 2005

110. Zhu Y H (unpublished results) 